\title{
Efficiency of Semantic Web Implementation on Cloud Computing: A Review
}

\author{
$1^{\text {st }}$ Kazheen Ismael Taher \\ Dept. of Information Technology \\ Duhok Polytechnic University \\ Duhok-Iraq \\ kajeen.ismael@gmail.com

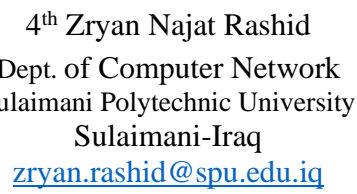

\author{
$2^{\text {nd }}$ Rezgar Hasan Saeed \\ Computer Science Dept. \\ Near East University \\ Cyprus \\ rezgarhasan1992@gmail.com \\ $5^{\text {th }}$ Lailan M. Haji \\ Computer science Dept. \\ University of Zakho \\ Duhok -Iraq \\ lailan.haji@uoz.edu.krd \\ $7^{\text {th }}$ Hivi Ismat Dino \\ Computer science Dept. \\ University of Zakho \\ Duhok -Iraq \\ hivi.dino@uoz.edu.krd \\ https://doi.org/10.48161/qaj.v1n3a72
}

\author{
$3^{\text {rd }}$ Rowaida Kh. Ibrahim \\ Computer science Dept. \\ University of Zakho \\ Duhok -Iraq \\ rowaida.ibrahim@uoz.edu.krd
}

\author{
$6^{\text {th }}$ Naaman Omar \\ Information Technology Dept. \\ Duhok Polytechnic University \\ Duhok-Iraq \\ naaman.omar@dpu.edu.krd
}

\begin{abstract}
Semantic web and cloud technology systems have been critical components in creating and deploying applications in various fields. Although they are selfcontained, they can be combined in various ways to create solutions, which has recently been discussed in depth. We have shown a dramatic increase in new cloud providers, applications, facilities, management systems, data, and so on in recent years, reaching a level of complexity that indicates the need for new technology to address such tremendous, shared, and heterogeneous services and resources. As a result, issues with portability, interoperability, security, selection, negotiation, discovery, and definition of cloud services and resources may arise. Semantic Technologies, which has enormous potential for cloud computing, is a vital way of re-examining these issues. This paper explores and examines the role of Semantic-Web Technology in the Cloud from a variety of sources. In addition, a "cloud-driven" mode of interaction illustrates how we can construct the semantic web and provide automated semantical annotations to web applications on a large scale by leveraging Cloud computing properties and advantages.
\end{abstract}

Keywords- Semantic web, Cloud Computing, Semantic Technologies, cloud-driven.

\section{INTRODUCTION}

Semantic innovations and cloud computing are two main fields that offer solutions to numerous information technology problems [1-3]. They all communicate, though, in different ways and for particular reasons. With the variation of their modes of interaction, the various modes of interaction have become essential to recognize and describe[4-6]. A thesis by [7] based on the analysis and analysis of semantic annotation, making an argument for using cloud computing framework to overcome some of its problems. In addition, the paper evaluates the numerous ways in which semantic technology and cloud computing interact and critically examines existing work in each location [8-11]. It then specifically reflects on how cloud computing can make the semantic web simpler and develop some of its capabilities [12-15]. The existing site consists mainly of papers that are only readable by humans, without the necessary components to facilitate machine comprehension [16-18]. This is because of the lack of knowledge of meaning for web papers. The semantic website focuses on technology to help computers comprehend online content through the use of structured data from annotation graphs to define their significance [19-21].

Cloud computing [22-24] It has emerged as a current technical idea aimed at providing a new vision of delivering high-cost Internet computing services based on an easy-touse pay-per-use paradigm [25-27]. However, due mainly to the large, shared, and the heterogeneous number of services 
and resources, this Technology's exponential growth has reached a degree of sophistication. More particularly, because these features are handled through various and nonstandard frameworks, cloud actors and even practitioners face the spectrum of cloud services and tools, control and access [28-33]. Also, the definitions given for cloud infrastructure and facilities can be vague, mostly due to the use of multiple semantics to discuss the same concepts [3436]. Conflicts come into being in this unwelcome yet necessary case, incompatibilities between cloud systems can occur, and far more human connections are also needed. This leads to significant problems that hinder the universal use of the Cloud from being encouraged [8, 32, 37].

Tim Berners-Semantic Lee's Web has gained increasing interest from industry and academia to raise the importance of Web information services and make them easily readable by machines through some primary technologies [32, 38, 39]. Indeed, a significant body of computer service literature has already provided help solutions focused on some of these innovations to resolve the aforementioned problems. Many of them can be used for cloud services and resources with necessary modifications [40-42]. However, relative to conventional web services, these components have specific features like those described in [22, 43, 44]. They were introducing some difficulties that restrict the applicability of these solutions in the real-life cloud scenario. As an example of the scenario, service exploration and selection in the Cloud, such a new approach must deal with complicated limitations and competitive negotiating support due to the diverse existence of cloud infrastructure and services and their development speed [32, 45].

\section{SEMANTIC TECHNOLOGY}

'semantic technology' is the collection of computer languages and standards with universal protocols and data formats, which permit a network of data that spans different fields $[46,47]$. As the name suggests, semantic technologies use formal semantics to provide meaning for digital records.

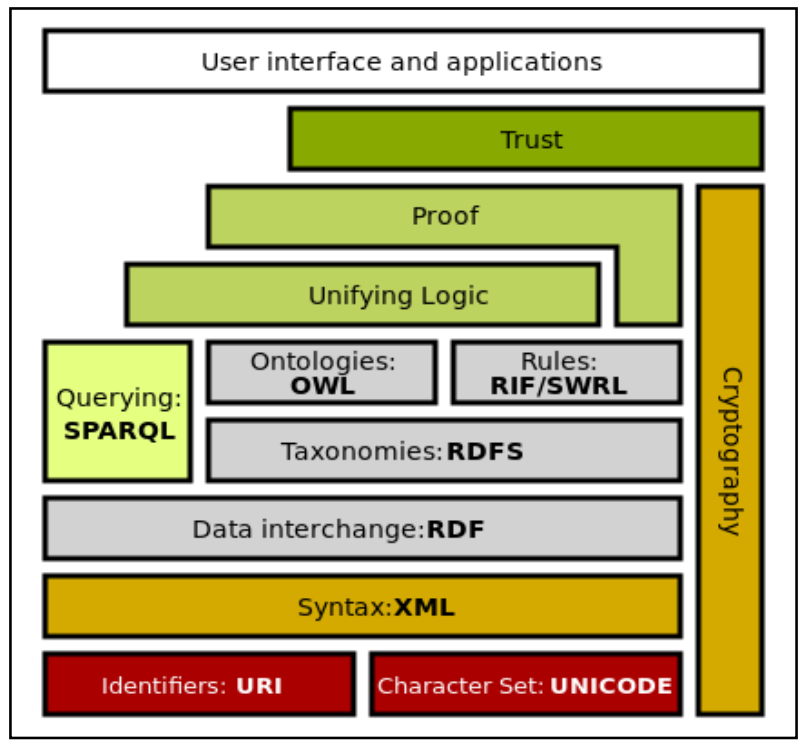

Figure1: The stack of semantic web technologies [48]
The Semantic Online focuses on the use of semantical technology to offer web documents with information about the records and data, employing ontology and semantical graph data bases. Semantic-web database annotation also means that these records can be interpreted and analyzed by computers, thus increasing the efficient and effective usage of web-based documents [49-51]. The semantic web technology stack, as shown in Figure1, is a wide variety of technologies and standards. They are employed during the creation of a semantic web for a range of functions and may be described as follows [48]:

- Unicode and URI [52] define the standards for defining semantic web objects and validating international character sets for data representation.

- The XML (eXtensible Markup Language) layer, including namespaces and XML Schema, allows the semantic-web and XML-based specifications to be integrated [53]. XML is responsible for providing standardized documents with a usable surface syntax without putting semantic constraints on what the documents stand for [54].

- RDF is a simple model of knowledge that relates to objects and their relationships. This enables annotation data to be portable across multiple platforms [55]. In addition to the RDFS (Resource Description Framework Schema) and RDF (Data Description Framework with Attributes) layers, the RDF (Information Description System) layer allows the Uniform Resource Identifiers [54] to use the schematic and syntactic vocabulary specifications.

- RDFS is a language that explains the properties and classes of RDF resources in which individual characteristics and classes at various abstraction levels generalize hierarchies [54].

- The Ontology Layer relies on the concept of ontological concepts, properties, and relationships. It also describes the characteristics of various terms that contribute to vocabulary evolution [56-58]. OWL (Web Ontology Language) on this layer is common and describes ontological component functions and interrelationships.

- RIF (Rule Interchange Format) It is a recursive acronym for web-based rule transfers for the Sparkle Protocol and the RDF Query Language. SPARQL is in contrast to Sparkle Protocol and RDF Query Language as recursive acronym. This is utilized when semantical databases for data formats such as RDF and JSON are queried. [54].

- The Cryptographic Layer guarantees encryption data security utilizing the different requirements present in the semantic web stack [52].

- The Unifying Logic Layer sets the rules for the semantic web, while the Proof Layer applies them. The Confidence Layer interacts with the Proof Layer to test the application process and verify the execution of the rules [52]. 


\section{III.CLOUD COMPUTING}

First of all, it is essential to clarify what cloud computing is and what it provides specifically. The Internet remote server can host, handle, and process data are known as cloud computing [59-61] in place of a personal computer or a local server. Access to a suitable network that makes it easier to contribute computational resources can be given on demand. The complex mixture of data from various data sources has been successfully approved and enabled [6264]. Cloud computing offers services that allow for the spread of over the Internet of viable computing resources. Cloud computing (or, more directly, Cloud computing) provides a range of computing resources per program accessible online and available online [65-67]. Introductory provisions such as computing and data storage are provided for such services. It can also be described as a recent computer-related model in which the acquisition of I.T. is provided a new business concept for businesses/organizations. This offers a new view of highperformance, internet-based computing networks in which computer-related services are supplied in a service format[37, 68, 69].

\section{Semantic Technologies for Cloud}

Numerous semantic innovations and implementations have been applied to cloud systems, rendering them semantic [70-72]. A semantic cloud facilitates a cloud platform's reliability about applications through various distribution models (IaaS, PaaS, and SaaS) [73, 74]. Semantic Technology such as RDF to model data for cloud providers and RDFS or OWL to create ontologies for cloud models are typically used to do this [75, 76]. Ontologies currently exist to provide metadata for the identification of cloud entities. Most of these, however, still require further development and enrichment [77-79].

\section{Cloud-Driven Semantic Web}

Providing an automated and consistent stream of software upgrades based on a workflow applies to a continuous delivery mechanism. This notification can be made to an entire degree possible, even many times a day. Integration into third-party solutions for container orchestration motors such as Kubernetes and Docker Swarm [80-82] should be made better. Software upgrades, including ontology, RDF graph databases, web data, and annotation details to ensure that the exactness and accuracy between components of a semantic annotation solution are maintained, require automated means to facilitate the continuity of such updates. In the cloud-driven semantic annotation mode, which is shown in Figure 2, the following characteristics are defined on this basis.

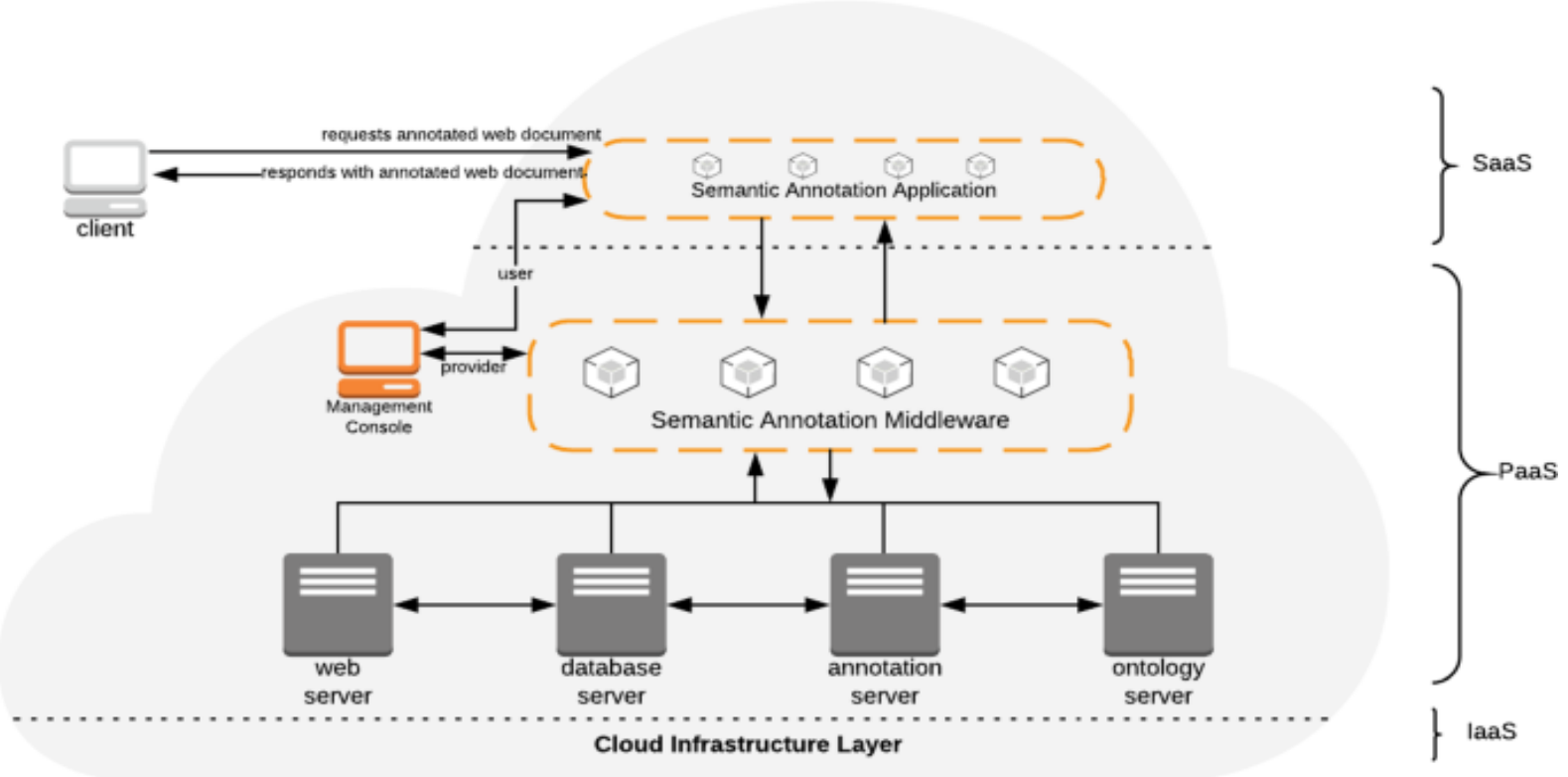

Figure 2: High-level semantic annotation powered by the Cloud [48]

\section{IV.LITERATURE REVIEW}

Kirrane et al. [83] Proposed a solution that underlined the use of hybrid techniques that collected qualitative and quantitative methodologies to address their respective constraints. This research is intended to improve and deepen the knowledge and guidelines of the Semantic Web via the use of a hybrid method which allows both qualitative and quantitative solutions to be used. They utilized the latter to assess the former and to reach critical conclusions regarding the advantages and disadvantages of the up and down techniques to identifying studies. They concentrated on researching and thinking about the past and, to a certain extent, upon the future.

Hsu and Lin. [84] developed a Linked Data Query Platform (LDQP) based on the machine learning integrated with Semantic Web in Framework Cloud Computing (IMLSWCCF). In addition, LDQP has been created to boost computing efficiency on Spark's cluster-cloud computing systems. They employed web semantology, Jena-based and OWL grammar, suggestions to construct a personalized 
intelligence system. Web technology An strategy sometimes utilized for a computer education is to categorize the items automatically, including K-nearest neighbors (K-NN) and K-means. In addition, cloud technology, including Spark and Apache Hadoop, is being utilized to improve Facebook postings and open data records on enormous quantities of processing. They have also employed cloud computing technologies such Spark and Apache Hadoop to make the processing of vast quantities of Facebook articles and open data records much more effective. According to user actions on Facebook, the result of the LDQP query may be updated and visually shown. In the context of Cloud Computing Framework (IMISWCCF), they suggested an integrated learning mechanism with semantic web that comprises of a connected unit of data, a machine learning unit, semantic web unit and cloud computing unit for smart cloud applications. In addition, IML-sweCF was proposed, and LDQP is adopted for validating its feasibility.

Iatrellis et al. [85] Presented a contemporary article on semantically improved cloud-based IT that blends learning pathways with workforce management skills as technical staff and management in a smart city municipality. The information offered combines a grammar system with a linguistically rich architecture to describe in details the gap in qualification for learning aims and the scope for improving abilities for city workers. The articles present the primary tools for modeling a CMUTE system that is developed and suggested. The study proposes the following in this respect: (a) Curriculum reform and interdisciplinary learning accelerated and universalized education in linked subject areas; and (c) technology businesses to train smart cities' workforces. A cloud-based method that blends semantic infrastructure with a rule based expert system to meet these needs, which is featured on paper as software (SaaS). The method offered builds on an ecosystem-based strategy, which involves all parties involved, directly or indirectly, in processing management competency with the software developed platform. They strive to enhance the professional by training the staff who work or work in municipalities that eventually become intelligent towns.

Nawaz et al. [77] Proposed various cloud SDL approaches by concentrating on their primary objective to usage in different cloud infrastructure activities, including provisioning, configuration, simulation, exploration, composition, collection, and service level agreements. In order to define their shared characteristics in various service activities, they used a common comparative criterion to characterize current literature on Cloud SDLs. The systematic literature review approach is adopted in their article. The literature is selected within a timeline using well-defined search queries according to this approach. They introduced the classification of Cloud SDLs in their section. Depending on the target, divide them further into Domain, distribution models of operation, and reach. Interesting findings are taken from the state-of-the-art SDLs in the Cloud. Furthermore, it also reveals the fear, Tures, as well as Cloud SDL limitations.

Modi et al. [86] presented an automated QoS strategy for matching, discovering and compiling cloud resources using the Semantic Web. To satisfy end users' expectations, the authors presented a novel approach for the development, discovery and composition of cloud-based services by means of the Semantic Web and Quality of Service (QoS) model. They take into account quality assurance and greater user satisfaction QoS characteristics such as connection, throughput, reaction time and cost. In order to boost customer happiness and Semantic Web, they focused on the development of an automated architecture and automation strategy for the cloud service lifecycle procedures, such as exploration, composition and collection. Using an efficiency and utilities measuring framework focused on a medical policy method (HDMS). Results from the test reveal that the suggested prototype works effectively for the specific cloud service collection of jobs. They offered a framework and approach to match, aggregate and compose cloud resources on the basis of the Semantic Web and QoS characteristics, such as availability, reaction time, output and cost. It will help end users to mix, sort and filter cloud services and will also introduce cloud service providers into a multi-cloud setting.

Das et al. [87] suggested implementing a semantic search engine in the cloud database that collects the related data for the user using semantic technologies. They would also like to illustrate the functioning of semantic searching with the Big Data correlation and its processing. They have also employed cloud computing technologies such Spark and Apache Hadoop to make the processing of vast quantities of Facebook articles and open data records much more effective. They were also used to approach machine training and to categorize things automatically, including $\mathrm{K}$ nearest neighbors $(\mathrm{K}-\mathrm{NN})$ and $\mathrm{K}$-means. These Big Data methods are used to search, making searching and collecting data pretty straightforward.

Parra-Royon et al. [88] proposed a semantic scheme for identifying and representing complete data mining services, considering both the supplier's service management (price, Service Level Agreement, authentication) and the concept of the workflow of datamining as a service. It is a solid commitment to paving the way for the industrialization and standardization of facilities for data mining. A collection of services from data mining companies has been identified to determine the scheme's validity, and an example of a complete service for a Random-Forest algorithm has been specified as a service. A lightweight vocabulary for the description and meaning of D.M. services in CC, dmcc-schema was introduced. The key objective is to identify D.M. resources for CC platforms, taking the L.D. Printed copies into account. The proposal aims to collect everything relevant to the concept of algorithms as a D.M. service and all the other things that make up the administration of a CC service. The other service specification ideas ignore this convergence, but DMC-Schema allows this gap to be overcome to build allin-one D.M. systems for Cloud-Computing environments.

Ouchaou et al. [89] The approach proposed intends to efficiently publish Cloud SaaS sources in sets by classification by domain to limit the search space and interconnect the SaaS services of the same domain with the concept-to-concept parameter (input/output similarity) into the semanticized network. The proposed method is supported by the multidimensional index system, the 
semantine Web and WordNet Domain Ontology. A driven publication procedure and a used prototype will lead to the assessment of the scheme by means of an exact data set corpus. In this research, Cloud SaaS services, including service publishing and discovery, are handled as an important need in any IT system, and in particular in the Cloud, for the effective management of resources and services through automated solutions for publishing and detection. Digital solutions have to deal directly with the diversity and expanding numbers of services and tools as corporate and consumer offers move into the cloud. The proposal focuses on a layout of cloud infrastructure based on multidimensional cloud index systems, the WordNet domain categorization, semantile administration of web resources.

Adedugbe et al. [90] It suggested a cloud-driven structure. It is a language study based on radical ontology, whether a natural language, such as English, French, German, German, or artificial languages, such as computer programs. Web-based information is the subject of this investigation. Metadata that can be derived from ontologies or a variety of ontologies are contributed in different ways to web papers to offer a broad context for the statistics given in the documents. In this research the semantic annotation of online documents gave a critical study of feasible alternatives to difficulties in general. The study offered a comprehensive approach to the method, the addition of feasible semantic annotation functions which meet the demands of the user and a dynamic solution.

Abascal et al. [10] developed a semantic smart integrated healthcare infrastructure incorporating semantic web and cloud computing. As follows, the remainder of the paper is structured. Centered on ontology and cloud computing, they suggested a Semantic Smart integrated healthcare infrastructure. If and when appropriate, the proposed architecture will connect and exchange health data with approved healthcare experts. In addition, by an ontology, real-time knowledge about the patient and its context is portrayed, making the research process more meaningful and relevant.

Mittal et al. [91] A Q\&A methodology has been devised for the analysis and collection of information from SLA data. They also built the knowledge library for Cloud SLAs, which forms the basis of many providers' Q\&A platform. To construct our framework, they have employed natural language processing and web methods (RDF, SPARQL, and Fuseki server). They also provide examples of how a client might measure, including service credit. They provide examples. The aim is to identify our cognitive agent utilizing a Q\&A System to assess cloud service legal documents utilizing a wide range of approaches including machine learning and text mining. The project aims at creating a Q\&A system for analyzing legal cloud services documents based on expertise derived from a variety of approaches, such as profound learning and text mining, in order to assess legal documents. Using the Q\&A methodology the client may input their cloud service inquiry, assess the information, link the entities and retrieve the information from the relevant knowledge graph. Multiple data features that indicate distinct validations and thresholds have been established. The method of calculating the service credit, too, may differ between providers.

\section{TABle 1: MaIn Finding FROM the Literature on Semantic Web AND Cloud Computing}

\begin{tabular}{|c|c|c|c|c|c|c|c|}
\hline Ref. & Years & Dataset & Objective & Methods & $\begin{array}{c}\text { Cloud } \\
\text { models }\end{array}$ & $\begin{array}{l}\text { Semantic web } \\
\text { technologies }\end{array}$ & Main finding \\
\hline [84] & 2020 & $\begin{array}{l}188 \text { Chinese } \\
\text { words }\end{array}$ & $\begin{array}{l}\text { Performs clustering via the K- } \\
\text { means algorithm specially } \\
\text { developed to classify open data } \\
\text { clusters. }\end{array}$ & $\begin{array}{l}\text { K-NN } \\
\text { K-means }\end{array}$ & Saas & $\begin{array}{l}\text { IMLSWCCF } \\
\text { LDQP } \\
\text { RDF } \\
\quad \text { OWL }\end{array}$ & $\begin{array}{l}\text { LDAP conducts Jieba's word } \\
\text { division analysis and stores the } \\
\text { analysis results using } 1420 \text { data } \\
\text { sets. }\end{array}$ \\
\hline$[83]$ & 2020 & $\begin{array}{l}\text { external } \\
\text { document and } \\
\text { corpus } \\
\text { domain export }\end{array}$ & $\begin{array}{l}\text { This paper aims to provide a } \\
\text { broader and more complete image } \\
\text { of Semantic Web topics and } \\
\text { developments. }\end{array}$ & $\begin{array}{l}\text { mixed } \\
\text { methods } \\
\text { Explore, } \\
\text { Saffron, } \\
\text { PoolParty }\end{array}$ & - & $\begin{array}{l}\text { L.D., RDF, } \\
\text { SPARQL, O.M., } \\
\text { O.E., SWS, OWL } \\
\text { Semantic Search }\end{array}$ & $\begin{array}{l}\text { The fundamental theme and } \\
\text { pattern analysis performed } \\
\text { through PoolParty did not show } \\
\text { any valuable results. The cross- } \\
\text { relationship of patterns outlined } \\
\text { by PoolParty, Rexplore, and } \\
\text { Saffron reveals that related } \\
\text { data, open data, and data } \\
\text { sources are on the upward } \\
\text { trend. }\end{array}$ \\
\hline$[85]$ & 2020 & $\begin{array}{l}\text { cybersecurity } \\
\text { analyst, data } \\
\text { scientist } \\
\text { and cloud } \\
\text { architect. }\end{array}$ & $\begin{array}{l}\text { Defining new career profiles for } \\
\text { those looking to work as } \\
\text { professionals in a smart city. }\end{array}$ & DevOps & SaaS & OWL, API & $\begin{array}{l}\text { As a result of this study, three } \\
\text { new occupations have been } \\
\text { identified: Smart-City IT- } \\
\text { Manager, Smart City Planner, } \\
\text { Smart City I.T. officer. }\end{array}$ \\
\hline [77] & 2019 & $\begin{array}{l}\text { service } \\
\text { description } \\
\text { language }\end{array}$ & $\begin{array}{l}\text { Deployment and } \\
\text { provisioning } \\
\text { languages }\end{array}$ & $\begin{array}{l}\text { SDL } \\
\text { CPS }\end{array}$ & $\begin{array}{l}\text { LaaS } \\
\text { PaaS } \\
\text { SaaS }\end{array}$ & $\begin{array}{l}\text { XML, DTD, } \\
\text { OWL, UML }\end{array}$ & $\begin{array}{c}\text { Cloud-based customer } \\
\text { subscriptions are compared } \\
\text { with cloud-based services and } \\
\text { utilities provided by service } \\
\text { providers. }\end{array}$ \\
\hline [86] & 2019 & $\begin{array}{l}\text { details in } \\
\text { separate data } \\
\text { repositories. }\end{array}$ & $\begin{array}{c}\text { Generate a collection of matching } \\
\text { services from various cloud } \\
\text { service providers by semantic } \\
\text { matching. }\end{array}$ & QoS & SaaS & SLA & $\begin{array}{l}\text { The test reveals that the } \\
\text { prototype proposed works well } \\
\text { for the given collection of } \\
\text { cloud-services tasks. }\end{array}$ \\
\hline
\end{tabular}




\begin{tabular}{|c|c|c|c|c|c|c|c|}
\hline [87] & 2019 & Big Data & $\begin{array}{l}\text { Build a prototype framework that } \\
\text { catches the user's concept via the } \\
\text { keyword list given. }\end{array}$ & API's & $\begin{array}{l}\text { LaaS } \\
\text { PaaS } \\
\text { SaaS }\end{array}$ & - & $\begin{array}{l}\text { A customer collected a large } \\
\text { amount of improper data after } \\
\text { wasting maximum time } \\
\text { browsing the information. }\end{array}$ \\
\hline [88] & 2019 & $\begin{array}{l}\text { ccdm:ML } \\
\text { ServiceInput }\end{array}$ & $\begin{array}{l}\text { Author Designing a Data Mining } \\
\text { service description enables a } \\
\text { complete service to be integrated } \\
\text { with a single and precise } \\
\text { definition. }\end{array}$ & $\begin{array}{l}\text { Random- } \\
\text { Forest } \\
\text { DM } \\
\text { SLA } \\
\text { KNN }\end{array}$ & 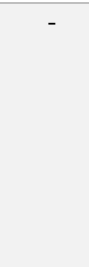 & $\begin{array}{l}\text { LD } \\
\quad \text { SPARQL }\end{array}$ & $\begin{array}{l}\text { Semantic classification and } \\
\text { overview of comprehensive } \\
\text { data mining resources. Takes } \\
\text { into account both the } \\
\text { management of the service by } \\
\text { the supplier and the definition } \\
\text { of the data mining workflow as } \\
\text { a service. }\end{array}$ \\
\hline [89] & 2018 & $\begin{array}{l}\text { real data set } \\
\text { corpus }\end{array}$ & $\begin{array}{l}\text { Cloud SaaS services of the same } \\
\text { Domain in the Semantic-Network } \\
\text { are interconnected by using the } \\
\text { similarity-measure. }\end{array}$ & - & SaaS & $\begin{array}{l}\text { XML } \\
\text { OWL }\end{array}$ & $\begin{array}{l}\text { Experimental findings have } \\
\text { confirmed the method of } \\
\text { publication. }\end{array}$ \\
\hline [90] & 2018 & $\begin{array}{c}\text { AeroDAML, } \\
\text { KIM, Seeker, } \\
\text { DBPedia } \\
\text { Spotlight, } \\
\text { OnTeA, Cogito } \\
\text { Intelligence API, } \\
\text { RDFaCE, GATE } \\
\text { Cloud and Onto- } \\
\text { Text }\end{array}$ & $\begin{array}{l}\text { Cloud computing is proposed as a } \\
\text { comprehensive service for the } \\
\text { transmission of semantic } \\
\text { annotation, }\end{array}$ & KIM & - & $\begin{array}{l}\text { XML } \\
\text { JSON }\end{array}$ & $\begin{array}{l}\text { Presents a Cloud-driven } \\
\text { platform to enable the delivery } \\
\text { of a web-based holistic } \\
\text { semantic annotation. }\end{array}$ \\
\hline [10] & 2018 & $\begin{array}{l}\text { Patient } \\
\text { healthcare } \\
\text { assistant }\end{array}$ & $\begin{array}{l}\text { Building an infrastructure that } \\
\text { requires patient care information } \\
\text { to be shared to be exploited by } \\
\text { multiple health institutions and } \\
\text { experts. Expand the level of } \\
\text { confidentiality and access to } \\
\text { information by asking for the } \\
\text { consent of the patient. }\end{array}$ & $\begin{array}{l}\text { get blood- } \\
\text { Pressure- } \\
\text { Report() } \\
\text { PHP 5, } \\
\text { jquery/ } \\
\text { JavaScript, } \\
\text { HTML5 } \\
\text { and } \\
\text { CSS } 3 \text {. }\end{array}$ & - & $\begin{array}{l}\text { OWL Ontology- } \\
\text { Model }\end{array}$ & $\begin{array}{l}\text { High detection precision can be } \\
\text { obtained via the proposed } \\
\text { tracking system. }\end{array}$ \\
\hline [91] & 2013 & $\begin{array}{l}\text { Hakia, } \\
\text { DuckDuckGo, } \\
\text { SenseBot }\end{array}$ & $\begin{array}{l}\text { Developing a search engine based } \\
\text { on semantic web and the results } \\
\text { are taken from the different search } \\
\text { engine such as Hakia, } \\
\text { DuckDuckGo, SenseBot and } \\
\text { adding the intelligent agents to } \\
\text { ignore the limitations of the search } \\
\text { engines }\end{array}$ & $\begin{array}{l}\text { tell factor } \\
\text { algorithm }\end{array}$ & $\begin{array}{l}\text { SaaS } \\
\text { PaaS } \\
\text { IaaS }\end{array}$ & intelligent agent & $\begin{array}{l}\text { The central concept of the } \\
\text { search engine results is to } \\
\text { highlight them from the } \\
\text { different search engines. }\end{array}$ \\
\hline
\end{tabular}

\section{DISCUSSION}

A great deal of focus has been paying in recent years to use semantic-web to increase the acceptance of cloud computing. This shows that all of the significant categories selected are selected. From Table 1 cited above and the corresponding explanation for each segment, each area's following insights can be found. The research, selection and agreement of cloud services, portability and Cloud interoperability, definition of services and cloud resources, and the cloud protection became the key to objective analysis. Methodologically, the tools were designed to apply their solutions, utilize algorithms for machine learning, semanticized APIs for programming and languages. The models are displayed in each solution for cloud models ( $\mathrm{S}$ to denote SaaS, $\mathrm{P}$ to denote PaaS, I to denote IaaS, $\mathrm{P}$ to denote PaaS). From Semantic-Web technologies, it is necessary to cite the semantic-web technologies used by researchers, i.e., OWL, LD, RDF/RDFs, SPARQL, SWRL, and RIF, etc. The majority of approaches were based on Semantic-Web StandardLanguages, namely OWL, XML, UML, and SPARQL.

\section{VI.CONCLUSION}

This article focused on several ways of interaction between semantic web and cloud technology to identify new potential. Development of the Semantic. Web sites In this study we provide a deep insight into the application of semantic technology in cloud computing. The study of ontology identifies the context of large assaults on online applications, numerous strategies employed by hackers and the source and objective of security vulnerabilities in these assaults. according to a reference paper survey. The policies to mitigate such assaults are laid out in this regard. This ontological paradigm makes it easier to gather the knowledge necessary to plan and implement methods of network assault.

\section{REFERENCES}

1. Hassan, R.J., et al., State of art survey for iot effects on smart city technology: challenges, opportunities, and solutions. Asian Journal of Research in Computer Science, 2021: p. 32-48. 
2. Salih, A.A., et al., Evolution of Mobile Wireless Communication to $5 G$ Revolution. Technology Reports of Kansai University, 2020. 62(5): p. 21392151.

3. Sallow, A.B., et al., An Investigation for Mobile Malware Behavioral and Detection Techniques Based on Android Platform. IOSR Journal of Computer Engineering (IOSR-JCE). 22(4): p. 1420.

4. Dino, H.I., et al., Impact of Process Execution and Physical Memory-Spaces on OS Performance.

5. Yazdeen, A.A., et al., FPGA implementations for data encryption and decryption via concurrent and parallel computation: A review. Qubahan Academic Journal, 2021. 1(2): p. 8-16.

6. Haji, S.H. and S.Y. Ameen, Attack and Anomaly Detection in IoT Networks using Machine Learning Techniques: A Review. Asian Journal of Research in Computer Science, 2021: p. 30-46.

7. Adedugbe, O., E. Benkhelifa, and R. Campion. Towards cloud driven semantic annotation. in 2017 IEEE/ACS 14th International Conference on Computer Systems and Applications (AICCSA). 2017. IEEE.

8. Abdullah, P.Y., et al., HRM system using cloud computing for Small and Medium Enterprises (SMEs). Technology Reports of Kansai University, 2020. 62(04): p. 04.

9. Ageed, Z.S., et al., Comprehensive survey of big data mining approaches in cloud systems. Qubahan Academic Journal, 2021. 1(2): p. 29-38.

10. Abatal, A., H. Khallouki, and M. Bahaj. A semantic smart interconnected healthcare system using ontology and cloud computing. in 2018 4th International Conference on Optimization and Applications (ICOA). 2018. IEEE.

11. Izadeen, G.Y. and S.Y. Ameen, Smart Android Graphical Password Strategy: A Review. Asian Journal of Research in Computer Science, 2021: p. 59-69.

12. Yahia, H.S., et al., Comprehensive survey for cloud computing based nature-inspired algorithms optimization scheduling. Asian Journal of Research in Computer Science, 2021: p. 1-16.

13. Abdulrahman, L.M., et al., A state of art for smart gateways issues and modification. Asian Journal of Research in Computer Science, 2021: p. 1-13.

14. Zeebaree, S., S. Ameen, and M. Sadeeq, Social media networks security threats, risks and recommendation: A case study in the kurdistan region. International Journal of Innovation, Creativity and Change, 2020. 13: p. 349-365.

15. Al-Sultan, M.R., S.Y. Ameen, and W.M. Abduallah, Real Time Implementation of Stegofirewall System. International Journal of Computing and Digital Systems, 2019. 8(5): p. 498-504.

16. Ageed, Z.S., et al., A survey of data mining implementation in smart city applications. Qubahan Academic Journal, 2021. 1(2): p. 91-99.

17. Zeebaree, S. and H.M. Yasin, Arduino based remote controlling for home: power saving, security and protection. International Journal of Scientific \& Engineering Research, 2014. 5(8): p. 266-272.

18. Sulaiman, M.A., et al., Analyzation Study for Gamification Examination Fields. Technol. Rep. Kansai Univ, 2020. 62(5): p. 2319-2328.

19. $\mathrm{Wu}, \mathrm{Y}$., et al. Automatically semantic annotation of network document based on domain knowledge graph. in 2017 IEEE International Symposium on Parallel and Distributed Processing with Applications and 2017 IEEE International Conference on Ubiquitous Computing and Communications (ISPA/IUCC). 2017. IEEE.

20. Zeebaree, S. and I. Zebari, Multilevel Client/Server Peer-to-Peer Video Broadcasting System. International Journal of Scientific \& Engineering Research, 2014. 5(8).

21. Shukur, H., et al., A State of Art Survey for Concurrent Computation and Clustering of Parallel Computing for Distributed Systems. Journal of Applied Science and Technology Trends, 2020. 1(4): p. 148-154.

22. Mell, P. and T. Grance, The NIST definition of cloud computing. 2011.

23. Rashid, Z.N., et al. Distributed cloud computing and distributed parallel computing: A review. in 2018 International Conference on Advanced Science and Engineering (ICOASE). 2018. IEEE.

24. Jacksi, K., et al. Clustering Documents based on Semantic Similarity using HAC and K-Mean Algorithms. in 2020 International Conference on Advanced Science and Engineering (ICOASE). 2020. IEEE.

25. Ageed, Z.S., et al., A state of art survey for intelligent energy monitoring systems. Asian Journal of Research in Computer Science, 2021: p. 46-61.

26. Sadeeq, M.M., et al., IoT and Cloud computing issues, challenges and opportunities: A review. Qubahan Academic Journal, 2021. 1(2): p. 1-7.

27. Sadeeq, M.A. and A.M. Abdulazeez. Neural Networks Architectures Design, and Applications: A Review. in 2020 International Conference on Advanced Science and Engineering (ICOASE). 2020. IEEE.

28. Martino, B.D., et al., An OWL ontology to support cloud portability and interoperability. International Journal of Web and Grid Services, 2015. 11(3): p. 303-326.

29. Di Martino, B., G. Cretella, and A. Esposito. Towards a unified owl ontology of cloud vendors' appliances and services at paas and saas level. in 2014 Eighth International Conference on Complex, Intelligent and Software Intensive Systems. 2014. IEEE.

30. Bellini, P., D. Cenni, and P. Nesi, Smart cloud engine and solution based on knowledge base. Procedia Computer Science, 2015. 68: p. 3-16.

31. Somasundaram, T.S., et al., Semantic-enabled CARE Resource Broker (SeCRB) for managing grid and cloud environment. The Journal of Supercomputing, 2014. 68(2): p. 509-556. 
32. Brabra, H., et al. Semantic web technologies in cloud computing: a systematic literature review. in 2016 IEEE International Conference on Services Computing (SCC). 2016. IEEE.

33. Ageed, Z.S., R.K. Ibrahim, and M.A. Sadeeq, Unified Ontology Implementation of Cloud Computing for Distributed Systems. Current Journal of Applied Science and Technology, 2020: p. 82-97.

34. Di Modica, G. and O. Tomarchio, Matching the business perspectives of providers and customers in future cloud markets. Cluster Computing, 2015. 18(1): p. 457-475.

35. Joshi, K.P., Y. Yesha, and T. Finin, Automating cloud services life cycle through semantic technologies. IEEE Transactions on Services Computing, 2012. 7(1): p. 109-122.

36. Alzakholi, O., et al., Comparison among cloud technologies and cloud performance. Journal of Applied Science and Technology Trends, 2020. 1(2): p. 40-47.

37. Rashid, Z.N., S.R. Zeebaree, and A. Shengul. Design and analysis of proposed remote controlling distributed parallel computing system over the cloud. in 2019 International Conference on Advanced Science and Engineering (ICOASE). 2019. IEEE.

38. Hitzler, P., M. Krotzsch, and S. Rudolph, Foundations of semantic web technologies. 2009: CRC press.

39. Selamat, S.A.A.-Z.A., Electronic Learning Management System Based on Semantic Web Technology: A Review. Int. J. Adv. Electron. Comput. Sci, 2017. 4(3): p. 1-6.

40. Woodworth, J., M.A. Salehi, and V. Raghavan. S3C: An architecture for space-efficient semantic search over encrypted data in the cloud. in 2016 IEEE International Conference on Big Data (Big Data). 2016. IEEE.

41. Hasan, D.A., et al., The impact of test case generation methods on the software performance: $A$ review. International Journal of Science and Business, 2021. 5(6): p. 33-44.

42. Ageed, Z., et al., Cloud computing resources impacts on heavy-load parallel processing approaches. IOSR Journal of Computer Engineering (IOSR-JCE), 2020. 22(3): p. 30-41.

43. Ibrahim, R., S. Zeebaree, and K. Jacksi, Survey on Semantic Similarity Based on Document Clustering. Adv. sci. technol. eng. syst. j, 2019. 4(5): p. 115-122.

44. Sallow, A., et al., Vaccine tracker. SMS reminder system: Design and implementation, 2020.

45. Ismail, S. and T. Shaikh. ALiterature REVIEW ON SEMANTIC WEB-UNDERSTANDING THE PIONEERS'PERSPECTIVE. in The Sixth International Conference on Computer Science, Engineering and Applications. 2016.

46. Coronado, M., C.A. Iglesias, and E. Serrano, Modelling rules for automating the Evented WEb by semantic technologies. Expert Systems with Applications, 2015. 42(21): p. 7979-7990.
47. Abdulqadir, H.R., et al., A study of moving from cloud computing to fog computing. Qubahan Academic Journal, 2021. 1(2): p. 60-70.

48. Adedugbe, O., et al., Leveraging cloud computing for the semantic web: review and trends. Soft Computing, 2020. 24(8): p. 5999-6014.

49. Berlanga, R., V. Nebot, and M. Pérez, Tailored semantic annotation for semantic search. Journal of Web Semantics, 2015. 30: p. 69-81.

50. Shukur, H., et al., Cloud computing virtualization of resources allocation for distributed systems. Journal of Applied Science and Technology Trends, 2020. 1(3): p. 98-105.

51. Fawzi, L.M., et al., Two Levels Alert Verification Technique for Smart Oil Pipeline Surveillance System (SOPSS). International Journal of Computing and Digital Systems, 2019. 8(02): p. 115-124.

52. Alam, F., et al., Towards a semantic web stack applicable for both RDF and topic maps: a survey. University of engineering and technology Taxila. Technical Journal, 2015. 20(2): p. 114.

53. Abdulla, A.I., et al., Internet of Things and Smart Home Security. Technol. Rep. Kansai Univ, 2020. 62(5): p. 2465-2476.

54. Ye, J., et al., Semantic web technologies in pervasive computing: A survey and research roadmap. Pervasive and Mobile Computing, 2015. 23: p. 1-25.

55. Gutiérrez, Y., D. Tomás, and I. Moreno, Developing an ontology schema for enriching and linking digital media assets. Future Generation Computer Systems, 2019. 101: p. 381-397.

56. Basu, A., Semantic web, ontology, and linked data, in Web services: concepts, methodologies, tools, and applications. 2019, IGI Global. p. 127-148.

57. Wang, X., X. Zhang, and M. Li, A survey on semantic sensor web: sensor ontology, mapping and query. International Journal of u-and e-Service, Science and Technology, 2015. 8(10): p. 325-342.

58. Abdulraheem, A.S., et al., Home automation system based on IoT. 2020.

59. Zebari, S.R. and N.O. Yaseen, Effects of Parallel Processing Implementation on Balanced LoadDivision Depending on Distributed Memory Systems. J. Univ. Anbar Pure Sci, 2011. 5(3): p. 5056.

60. Haji, L.M., et al., Impact of cloud computing and internet of things on the future internet. Technology Reports of Kansai University, 2020. 62(5): p. 2179-2190.

61. Kareem, F.Q., et al., A survey of optical fiber communications: challenges and processing time influences. Asian Journal of Research in Computer Science, 2021: p. 48-58.

62. Grigoras, D. and P. Gepner. The Distributed Mobile Cloud Supporting the Internet of Things. in 2015 14th International Symposium on Parallel and Distributed Computing. 2015. IEEE.

63. Malallah, H., et al., A Comprehensive Study of Kernel (Issues and Concepts) in Different 
Operating Systems. Asian Journal of Research in Computer Science, 2021: p. 16-31.

64. Omer, M.A., et al., Efficiency of malware detection in android system: A survey. Asian Journal of Research in Computer Science, 2021: p. 59-69.

65. Qaqos, N.N., S.R. Zeebaree, and B.K. Hussan, Opnet Based Performance Analysis and Comparison Among Different Physical Network Topologies. Academic Journal of Nawroz University, 2018. 7(3): p. 48-54.

66. Yasin, H.M., et al., IoT and ICT based Smart Water Management, Monitoring and Controlling System: A Review. Asian Journal of Research in Computer Science, 2021: p. 42-56.

67. Rashid, Z.N., S.R. Zeebaree, and A. Sengur, Novel Remote Parallel Processing Code-Breaker System via Cloud Computing.

68. Sahmim, S. and H. Gharsellaoui, Privacy and security in internet-based computing: cloud computing, internet of things, cloud of things: a review. Procedia computer science, 2017. 112: p. 1516-1522.

69. Omar, N.R., et al., Enhancing OS Memory Management Performance: A.

70. Ibrahim, I.M., Task scheduling algorithms in cloud computing: A review. Turkish Journal of Computer and Mathematics Education (TURCOMAT), 2021. 12(4): p. 1041-1053.

71. Mohammed, S.A., et al., GPU Concepts and Graph Application Challenges: A.

72. Jijo, B.T., et al., A comprehensive survey of $5 G$ mm-wave technology design challenges. Asian Journal of Research in Computer Science, 2021: p. $1-20$.

73. Zebari, I.M., S.R. Zeebaree, and H.M. Yasin. Real Time Video Streaming From Multi-Source Using Client-Server for Video Distribution. in 2019 4th Scientific International Conference Najaf (SICN). 2019. IEEE.

74. Abdullah, S.M.S.A., et al., Multimodal emotion recognition using deep learning. Journal of Applied Science and Technology Trends, 2021. 2(02): p. 52-58.

75. Yasin, H.M., S.R. Zeebaree, and I.M. Zebari. Arduino Based Automatic Irrigation System: Monitoring and SMS Controlling. in 2019 4th Scientific International Conference Najaf (SICN). 2019. IEEE.

76. Sadeeq, M.A. and S. Zeebaree, Energy management for internet of things via distributed systems. Journal of Applied Science and Technology Trends, 2021. 2(02): p. 59-71.

77. Nawaz, F., A. Mohsin, and N.K. Janjua, Service description languages in cloud computing: stateof-the-art and research issues. Service oriented computing and applications, 2019. 13(2): p. 109125.

78. Haji, S.H., et al., Comparison of Software Defined Networking with Traditional Networking. Asian Journal of Research in Computer Science, 2021: p. $1-18$.
79. Maulud, D.H., et al., State of art for semantic analysis of natural language processing. Qubahan Academic Journal, 2021. 1(2): p. 21-28.

80. Garg, S. and S. Garg. Automated cloud infrastructure, continuous integration and continuous delivery using docker with robust container security. in 2019 IEEE Conference on Multimedia Information Processing and Retrieval (MIPR). 2019. IEEE.

81. Sadeeq, M., et al., Impact of Electronic Commerce on Enterprise Business. Technol. Rep. Kansai Univ, 2020. 62(5): p. 2365-2378.

82. Sadeeq, M.A., et al. Internet of Things security: a survey. in 2018 International Conference on Advanced Science and Engineering (ICOASE). 2018. IEEE.

83. Kirrane, S., et al., A decade of Semantic Web research through the lenses of a mixed methods approach. Semantic Web, 2020(Preprint): p. 1-27.

84. Hsu, I.C. and Y.H. Lin, Integrated machine learning with semantic web for open government data recommendation based on cloud computing. Software: Practice and Experience, 2020. 50(12): p. 2293-2312.

85. Iatrellis, O., et al., Cloud computing and semantic web technologies for ubiquitous management of smart cities-related competences. Education and Information Technologies, 2021. 26(2): p. 21432164.

86. Modi, K.J. and S. Garg, A QoS-based approach for cloud-service matchmaking, selection and composition using the Semantic Web. Journal of Systems and Information Technology, 2019.

87. Das, N.N., et al. Semantic Big Data Searching in Cloud Storage. in 2019 International Conference on Machine Learning, Big Data, Cloud and Parallel Computing (COMITCon). 2019. IEEE.

88. Parra-Royon, M., G. Atemezing, and J.M. BenitezSanchez, Semantics of Data Mining Services in Cloud Computing. IEEE Transactions on Services Computing, 2020.

89. Ouchaou, L., et al. Semantic Networks Based Approach for SaaS Management in Cloud Computing. in 2018 International Conference on Smart Communications in Network Technologies (SaCoNeT). 2018. IEEE.

90. Adedugbe, O., E. Benkhelifa, and R. Campion. A cloud-driven framework for a holistic approach to semantic annotation. in 2018 Fifth International Conference on Social Networks Analysis, Management and Security (SNAMS). 2018. IEEE.

91. Mittal, S., et al. A question and answering system for management of cloud service level agreements. in 2017 IEEE 10th International Conference on Cloud Computing (CLOUD). 2017. IEEE. 